\title{
Tranilast prevents renal interstitial fibrosis by blocking mast cell infiltration in a rat model of diabetic kidney disease
}

\author{
DAN-DAN YIN, JUN-HUI LUO, ZHU-YE ZHAO, YING-JUN LIAO and YING LI
}

\author{
Department of Nephrology, The Second Xiangya Hospital, Central South University, \\ Key Laboratory of Kidney Disease and Blood Purification in Hunan, Changsha, Hunan 410011, P.R. China
}

Received March 2, 2017; Accepted August 21, 2017

DOI: $10.3892 / \mathrm{mmr} .2018 .8776$

\begin{abstract}
Renal interstitial fibrosis is a final pathway that is observed in various types of kidney diseases, including diabetic kidney disease (DKD). The present study investigated the effect of tranilast on renal interstitial fibrosis and the association between its role and mast cell infiltration in a rat model of DKD. A total of 30 healthy 6-week-old male Sprague-Dawley rats were randomly divided into the following four groups: Normal control group; DKD model group; low-dose tranilast group (200 mg/kg/day); and high-dose tranilast group (400 mg/kg/day). The morphological alterations of tubulointerstitial fibrosis were evaluated by Masson's trichrome staining, while mast cell infiltration into the renal tubular interstitium was measured by toluidine blue staining and complement $\mathrm{C} 3 \mathrm{a}$ receptor $1(\mathrm{C} 3 \mathrm{aR})$ immunohistochemical staining (IHC). The expression of fibronectin (FN), collagen I (Col-I), stem cell factor (SCF) and proto-oncogene c-kit (c-kit) was detected by IHC, western blotting and reverse transcription-quantitative-polymerase chain reaction. The results demonstrated that tubulointerstitial fibrosis and mast cell infiltration were observed in DKD model rats, and this was improved dose-dependently in the tranilast treatment groups. The expression of FN, Col-I, SCF and c-kit mRNA and protein was upregulated in the tubulointerstitium of DKD model rats compared with the normal control rats, and tranilast inhibited the upregulated expression of these markers. Furthermore, the degree of SCF and c-kit expression demonstrated a
\end{abstract}

Correspondence to: Dr Ying Li, Department of Nephrology, The Second Xiangya Hospital, Central South University, Key Laboratory of Kidney Disease and Blood Purification in Hunan, 139 Middle Renmin Road, Changsha, Hunan 410011, P.R. China

E-mail: liyingdoctor@163.com

Abbreviations: Col-I, collagen I; C3aR, complement C3a receptor 1; DKD, diabetic kidney disease; ESRD, end-stage renal disease; FN, fibronectin; IHC, immunohistochemical staining; SCF, stem cell factor; Scr, serum creatinine; TGF, transforming growth factor; UAER, urinary albumin excretion rate

Key words: tranilast, diabetic kidney disease, renal interstitial fibrosis, mast cells significant positive correlation with C3aR-positive mast cells and the markers of renal interstitial fibrosis. The results of the present study indicate that mast cell infiltration may promote renal interstitial fibrosis via the SCF/c-kit signaling pathway. Tranilast may prevent renal interstitial fibrosis through inhibition of mast cell infiltration mediated through the SCF/c-kit signaling pathway.

\section{Introduction}

Diabetic kidney disease (DKD) is the leading cause of kidney failure in patients with diabetes. Renal interstitial fibrosis may occur during the prophase of DKD and lead to the deterioration of renal function, independently of the glomerular lesions (1-3). However, the underlying mechanism of renal interstitial fibrosis in DKD remains to be fully elucidated. DKD has long been considered a non-inflammatory disease. However, certain studies previously reported that inflammation serves an important role in the pathogenesis of DKD and various types of inflammatory cells were involved in the occurrence of DKD $(4,5)$. It has also been reported that mast cells, derived from cluster of differentiation (CD) 34-positive multipotent bone marrow progenitor cells, may be one type of inflammatory cell that participate in the process of renal interstitial fibrosis in DKD (6), however, the specific mechanism remains unclear.

Tranilast [N-(3',4'-dimethoxycinnamic)-anthranilic acid] is a cell membrane stabilizer that has been widely used in the treatment of inflammatory diseases due to its role in inhibiting the release of histamine and other chemical mediators (7). Previous studies have demonstrated that tranilast attenuates renal interstitial fibrosis in the rat model of obstructive nephropathy (8), suppresses the progression of peritoneal fibrosis in rats with chronic renal failure and decreases fibrosis in myocardial infarction $(9,10)$. It has also been reported that tranilast inhibits the release of transforming growth factor (TGF)- $\beta 1$, decreases the accumulation of extracellular matrix and suppresses oxidative stress $(11,12)$. However, the role and mechanisms underlying the effects of tranilast on renal interstitial fibrosis in DKD are unclear. In the present study, the association between mast cell infiltration and renal interstitial fibrosis of DKD was analyzed, and the role and mechanisms by which tranilast inhibits renal interstitial fibrosis were investigated. 


\section{Materials and methods}

Rat model of DKD and experimental grouping. A total of 30 healthy male Sprague-Dawley rats (6-weeks old; $181.65 \pm 5.15 \mathrm{~g}$ ) were purchased from the Animal Department at Xiangya Medical School, Central South University (Changsha, China). All rats had free access to food and water with a 12 -h dark/light cycle in a climate-controlled room (temperature, $18-25^{\circ} \mathrm{C}$; humidity, $65-80 \% ; \mathrm{CO}_{2}, 0.03 \%$ ). Following feeding under adaptation conditions for 3 days, rats were randomly divided into normal control $(n=6)$ and DKD model $(n=24)$ groups. The normal control animals were fed with normal food and received once daily intraperitoneal injection of citrate buffer $[0.1 \mathrm{~mol} / \mathrm{l},(\mathrm{pH} 4.5)]$ at a dose of $10 \mathrm{ml} / \mathrm{kg}$, while the rat model of DKD was performed as described previously $(13,14)$. The rats were fed with a high-sugar and high-fat diet for 8 weeks followed by once daily intraperitoneal injection of streptozotocin $(30 \mathrm{mg} / \mathrm{kg}$; Sigma-Aldrich; Merck KGaA, Darmstadt, Germany) dissolved in citrate buffer. Blood and urine glucose was detected $72 \mathrm{~h}$ following streptozotocin injection. The diabetes model was considered to be successful when fasting blood glucose was $>13.8 \mathrm{mmol} / 1$, random blood glucose was $>16.7 \mathrm{mmol} / 1$, and urine glucose, detected by Benedict's test, was ++++. The rat model of DKD was considered to be successfully established if urine protein, determined by the Lowry procedure, was $>30 \mathrm{mg}$ for $24 \mathrm{~h}$ following the establishment of the diabetes model. During the experiment, blood glucose was measured every 3 days using a tail vein sample. A certain amount of long-acting insulins (0.4-3.2 units) was injected into the rats of which blood glucose was higher than $26.0 \mathrm{mmol} / \mathrm{l}$, but random blood glucose was maintained above $16.7 \mathrm{mmol} / \mathrm{l}$.

DKD model rats were subsequently randomly divided into the following three groups ( $\mathrm{n}=8$ for each group): DKD model group; low-dose tranilast group $(200 \mathrm{mg} / \mathrm{kg} / \mathrm{day})$ and high-dose tranilast group (400 mg/kg/day) (11). The DKD model rats were only fed $1.5 \%$ sodium carboxymethyl cellulose solution, while the rats treated with tranilast had tranilast administrated twice daily, which was dissolved in $1.5 \%$ sodium carboxymethyl cellulose solution. By the 8th week following tranilast treatment, the $24 \mathrm{~h}$ urine samples of all rats were collected to determine the albumin concentrations, and rats were intraperitoneally anesthetized with ketamine/xylazine $(80 \mathrm{mg} / \mathrm{kg}+10 \mathrm{mg} / \mathrm{kg})$ and sacrificed. Blood samples for measuring creatinine were obtained from the abdominal aorta prior to the kidneys being harvested and weighed. All animals used in the present study were appropriately processed following protocols approved in advance by the Animal Care and Use Committee at Central South University. All procedures performed in experiments with animals were in accordance with the ethical standards of the Department of Nephrology, Second Xiangya Hospital at which the present study was conducted.

Biochemical analysis. In the present study, the levels of blood glucose were estimated using an Accu-Chek glucometer (Roche Diagnostics, Basel, Switzerland). To assess the urinary albumin excretion rate (UAER), the albumin concentrations for the urine samples were detected using the Urine micro-albumin assay kit (Nanjing Jiancheng Bioengineering Institute, Nanjing, China). The serum for detecting creatinine were collected by centrifugation of whole blood $(0.5 \mathrm{ml}$ each of samples) at 3,000 x g for $15 \mathrm{~min}$ following blood agglutination at room temperature, and serum creatinine (Scr) was detected using a BioAssay Systems Creatinine assay kit (BioAssay Systems, Hayward, CA, USA).

Masson's trichrome staining for detecting renal tubulointerstitial fibrosis. The 4\% paraformaldehyde-fixed (at room temperature for $24 \mathrm{~h}$ ), paraffin-embedded tissue sections $(3-\mu \mathrm{m})$ were dewaxed routinely in xylene for $10 \mathrm{~min}$ and then in graded alcohol (100, 95, 80 and 70\%), 5 min each, and washed in $\mathrm{dH}_{2} \mathrm{O}$. Hematoxylin was used to stain nuclei for $3 \mathrm{~min}$ at room temperature. Following flushing with water for 30-60 sec, sections were stained in Ponceau acid fuchsin solution (ponceau $0.7 \mathrm{~g}$, acid fuchsin $0.3 \mathrm{~g}$, distilled water $99 \mathrm{ml}$ and glacial acetic acid $1 \mathrm{ml}$ ) for 5-10 min, rinsed with tap water for $1 \mathrm{~min}$, stained in $1 \%$ phosphomolybdic acid solution for $1 \mathrm{~min}$ and transferred into $2 \%$ aniline blue liquid to dye for $3 \mathrm{~min}$. Following washing with water, sections were dehydrated in graded ethanol and made transparent in xylene for $1 \mathrm{~min}$, and subsequently enclosed with neutral gum. All the procedures were done at room temperature. Collagen fibers were stained blue. Slides were observed under a light microscope (Olympus CX41; Olympus Corporation, Tokyo, Japan). Images were taken of 10 non-overlapping interstitial areas in each section. A high-definition color medical analysis system with image analysis software (HMIAS-2000; Qianping Image Technology Co., Ltd., Wuhan, China) was used for automatic measurement and analysis, and the percentage of tubulointerstitial area in the total area visualized in each section was calculated.

Toluidine blue staining. Modified toluidine blue staining was performed to detect mast cells $(15,16)$. Paraffin sections $(3-\mu \mathrm{m})$ were deparaffinized and rehydrated according to the above procedures, and immersed in toluidine blue for $3 \mathrm{~min}$ and differentiated with $0.5 \%$ glacial acetic acid for $10-20 \mathrm{sec}$ until mast cell nuclei were visible at room temperature. Tissue sections were cleared with xylene and sealed with neutral gum, and subsequently photographed under a light microscope. A total of three images at high magnification (x200) were randomly selected for calculating the number of mast cells.

Immunohistochemical staining (IHC). Paraffin sections $(3-\mu \mathrm{m})$ were dewaxed and hydrated with the above method, and immersed in $0.01 \mathrm{~mol} / 1$ citrate buffer $(\mathrm{pH} 6.0)$ at $90^{\circ} \mathrm{C}$ for $5 \mathrm{~min}$ for microwave antigen retrieval. Sections were then incubated with $3 \% \mathrm{H}_{2} \mathrm{O}_{2}$ for $10 \mathrm{~min}$ at room temperature to eliminate endogenous peroxidase activity prior to blocking in $10 \%$ goat serum (Beyotime Institute of Biotechnology, Haimen, China) for $30 \mathrm{~min}$ at $37^{\circ} \mathrm{C}$. Sections were subsequently incubated with anti-complement $\mathrm{C} 3 \mathrm{a}$ receptor $1(\mathrm{C} 3 \mathrm{aR}$; 1:200; cat. no. sc-20138) and anti-proto-oncogene c-kit (c-kit; 1:400; cat. no. sc-5535) polyclonal antibodies (Santa Cruz Biotechnology Inc., Dallas, TX, USA), anti-fibronectin (FN; 1:400; cat. no. BA1772) and anti-stem cell factor (SCF; 1:400; cat. no. A01254) polyclonal antibodies (Boster Biological Technology Co., Ltd., Wuhan, China), and anti-collagen I polyclonal antibody (Col-I; 1:400; cat. no. T40227R; Meridian Life Science, Inc., Memphis, TN, USA) overnight at $4^{\circ} \mathrm{C}$. 
Following rinsing, the sections were incubated with horseradish peroxidase-labeled goat anti-rabbit immunoglobulin (Ig)G secondary antibodies for $1 \mathrm{~h}$ at $37^{\circ} \mathrm{C}(1: 500$; cat. no. ab6721; Abcam, Cambridge, UK), stained with 3,3'-diaminobenzidine for 30-60 sec and counterstained with hematoxylin for $3 \mathrm{~min}$ at room temperature. Negative controls for specific labeling were performed in parallel by replacing the primary antibody with a normal rabbit serum (cat. no. A7016; Beyotime Institute of Biotechnology). The slides were examined and photographed with a light microscope (magnification, x200). The Image-Pro Plus version 6.0 image analysis system (Media Cybernetics, Inc., Rockville, MD, USA) was used to measure the optical density of the positive area. The average optical density was used to represent the expression level of C3aR, FN, Col-I, SCF and c-kit.

Western blotting analysis. A total of 50-100 mg of kidney tissues were ground in liquid nitrogen and homogenized in $500 \mu 1$ pre-cooled radioimmunoprecipitation lysis buffer (cat. no. P0013B; Beyotime Institute of Biotechnology) at $4^{\circ} \mathrm{C}$ The lysate was cleared by centrifugation at $12,000 \mathrm{x} \mathrm{g}$ for $20 \mathrm{~min}$ at $4^{\circ} \mathrm{C}$. Protein concentration was determined using a bicinchoninic assay kit (Beyotime Institute of Biotechnology). Subsequently, 20-30 mg soluble lysates were loaded in each lane and separated by 8 or $10 \%$ SDS-PAGE gel electrophoresis and electrophoretically transferred to polyvinylidene difluoride membranes. Membranes were blocked with 5\% nonfat dry milk in TBS/0.5\% Tween-20 for $1 \mathrm{~h}$ at room temperature, washed with TBS/Tween-20 and incubated with FN (cat. no. ab2413), Col-I (cat. no. ab34710), SCF (cat. no. ab101072) and c-kit (cat. no. ab46758) polyclonal antibodies (Abcam, Cambridge, UK) at 1:1,000 dilution overnight at $4^{\circ} \mathrm{C}$. Blots were rinsed with TBS/Tween-20 and subsequently incubated with horseradish-peroxidase-conjugated secondary antibodies (at room temperature for $1 \mathrm{~h})$, including goat anti-rabbit $\operatorname{IgG}(1: 4,000$; cat. no. ab6721) and rabbit anti-goat IgG (1:4,000; cat. no. ab97100) (Abcam, Cambridge, UK). Following washing with TBS/Tween-20, the blots were developed with enhanced chemiluminescence reagents (GE Healthcare, Chicago, IL, USA). The density of the identified bands was quantified by densitometry using ImageQuant software (version 5.2; Molecular Dynamics, Sunnyvale, CA, USA). Values were normalized with respect to $\beta$-actin $(1: 4,000$; cat. no. ab8227; Abcam, Cambridge, UK) expression.

Reverse transcription-quantitative polymerase chain reaction $(R T-q P C R)$ analysis. Tissue expression of FN, Col-I, SCF and c-kit mRNA was assessed by RT-qPCR. A TRIzol ${ }^{\circledR}$ RNA extraction kit (Invitrogen; Thermo Fisher Scientific, Inc., Waltham, MA, USA) was used to extract total RNA from the renal tissue. Total RNA was used for cDNA synthesis according to the instructions in the RevertAid First Strand cDNA Synthesis kit (Fermentas; Thermo Fisher Scientific, Inc.). Gene sequences were verified in the NCBI GenBank (https://www.ncbi.nlm.nih.gov/genbank/) and primers were designed according to primer design principles using Primer Premier version 5.0 (Premier Biosoft International, Palo Alto, CA, USA) and purchased from Sangon Biotech Co., Ltd. (Shanghai, China). The primer sequences are presented in Table I. qPCR amplification of the products was performed
Table I. Primer sequences for quantitative polymerase chain reaction.

\begin{tabular}{ll}
\hline Gene & \multicolumn{1}{c}{ Primer } \\
\hline FN & F:5'-TGACAACTGCCGTAGACCTGG-3' \\
& R: 5'-TACTGGTTGTAGGTGTGGCCG-3' \\
Col-I & F: 5'-TGGCAAGAACGGAGATGA-3' \\
& R: 5'-AGCTGTTCCAGGCAATCC-3' \\
SCF & F: 5'-AGGCTCATTCGTCTGCTCTG-3' \\
& R: 5'-CTACCCATGTCCACCTTTCT-3' \\
c-kit & F: 5'-GGCCTAGCCAGAGACATCAG-3' \\
& R: 5'-GAGAGGCTGTGTGGAAGAGG-3' \\
$\beta$-actin & F: 5'-CCCATCTATGAGGGTTACGC-3' \\
& R: 5'-TTTAATGTCACGCACGATTTC-3'
\end{tabular}

FN, fibronectin; F, forward; R, reverse; Col-I, collagen-I; SCF, stem cell factor; c-kit, proto-oncogene c-kit.

on an ABI 7300 Real Time PCR system (Applied Biosystems; Thermo Fisher Scientific, Inc.) using SYBR GreenER ${ }^{\circledR}$ qPCR SuperMix Universal kit (Invitrogen; Thermo Fisher Scientific, Inc.) under the following reaction conditions: $50^{\circ} \mathrm{C}$ for $2 \mathrm{~min}$ and $95^{\circ} \mathrm{C}$ for $10 \mathrm{~min}$; 40 cycles of $95^{\circ} \mathrm{C}$ for $10 \mathrm{sec}, 60^{\circ} \mathrm{C}$ for $60 \mathrm{sec}$ and $72^{\circ} \mathrm{C}$ for $60 \mathrm{sec}$; final step for $10 \mathrm{~min}$ at $72^{\circ} \mathrm{C}$. The qPCR was repeated three times for each gene. Relative quantification of gene expression was performed using the $2^{-\Delta \Delta \mathrm{Cq}}$ method with $\beta$-actin as an endogenous control (17).

Statistical analysis. SPSS software (version 17.0; SPSS, Inc., Chicago, IL, USA) was used for statistical analysis. The results are presented as mean \pm standard deviation. Data were analyzed using one-way analysis of variance or the Kruskal-Wallis test. Pearson correlation analysis was performed to determine the correlation between the expression of SCF and c-kit with the infiltration of mast cells and indices of renal interstitial fibrosis. $\mathrm{P}<0.05$ was considered to indicate a statistically significant difference.

\section{Results}

The effect of tranilast on the general condition and biochemical indices of DKD rats. The DKD rats demonstrated polydipsia, polyphagia, polyuria and other symptoms. Compared with the normal control group, the body weight of DKD model rats was significantly reduced, while the kidneys became bigger and heavier, and the kidney weight/body mass index was significantly increased $(\mathrm{P}<0.05$; Table II). Blood glucose, UAER and Scr concentrations were significantly increased in the DKD model group compared with the normal control group $(\mathrm{P}<0.05$; Table II). There was no significant difference in the body weight, the kidney weight/body mass index, UAER, Scr and blood glucose level among different tranilast groups and the DKD model group $(\mathrm{P}>0.05)$.

Tranilast reduces mast cell infiltration in the kidneys of DKD rats. Toluidine blue staining and $\mathrm{IHC}$ of $\mathrm{C} 3 \mathrm{aR}$ was performed to detect mast cells in the renal interstitium. Toluidine blue 
Table II. The general condition and biochemical indexes of rats in different groups following 8-week tranilast treatment.

\begin{tabular}{|c|c|c|c|c|c|}
\hline Groups & $\begin{array}{l}\text { Body } \\
\text { mass, g }\end{array}$ & $\begin{array}{l}\text { Kidney weight/ } \\
\text { body weight, g/kg }\end{array}$ & $\begin{array}{c}\text { Blood glucose, } \\
\mathrm{mmol} / \mathrm{l}\end{array}$ & $\mathrm{Scr}, \mu \mathrm{mol} / 1$ & UAER, mg/24 h \\
\hline Control & $715.00 \pm 17.48$ & $6.24 \pm 0.48$ & $5.60 \pm 0.30$ & $60.30 \pm 7.20$ & $0.38 \pm 0.01$ \\
\hline DKD & $460.82 \pm 40.90^{\mathrm{a}}$ & $10.00 \pm 0.92^{\mathrm{a}}$ & $31.10 \pm 3.60^{\mathrm{a}}$ & $89.00 \pm 20.40^{\mathrm{a}}$ & $1.31 \pm 0.25^{\mathrm{a}}$ \\
\hline $\begin{array}{l}\text { Low-dose tranilast, } \\
200 \mathrm{mg} / \mathrm{kg} / \text { day }\end{array}$ & $460.32 \pm 56.50^{\mathrm{a}}$ & $9.43 \pm 1.47^{\mathrm{a}}$ & $23.80 \pm 6.90^{\mathrm{a}}$ & $76.40 \pm 12.90^{\mathrm{a}}$ & $1.27 \pm 0.85^{\mathrm{a}}$ \\
\hline $\begin{array}{l}\text { High-dose tranilast, } \\
400 \mathrm{mg} / \mathrm{kg} / \mathrm{day}\end{array}$ & $462.13 \pm 34.93^{\mathrm{a}}$ & $10.73 \pm 1.29^{\mathrm{a}}$ & $30.20 \pm 2.50^{\mathrm{a}}$ & $76.90 \pm 12.90^{\mathrm{a}}$ & $1.25 \pm 0.67^{\mathrm{a}}$ \\
\hline
\end{tabular}

Control, $\mathrm{n}=6$; DKD, $\mathrm{n}=8$; low-dose tranilast, $\mathrm{n}=8$; high-dose tranilast, $\mathrm{n}=8$. ${ }^{\mathrm{a}} \mathrm{P}<0.05$ vs. control group. Scr, serum creatinine; UAER, urinary albumin excretion rate; DKD, diabetic kidney disease.

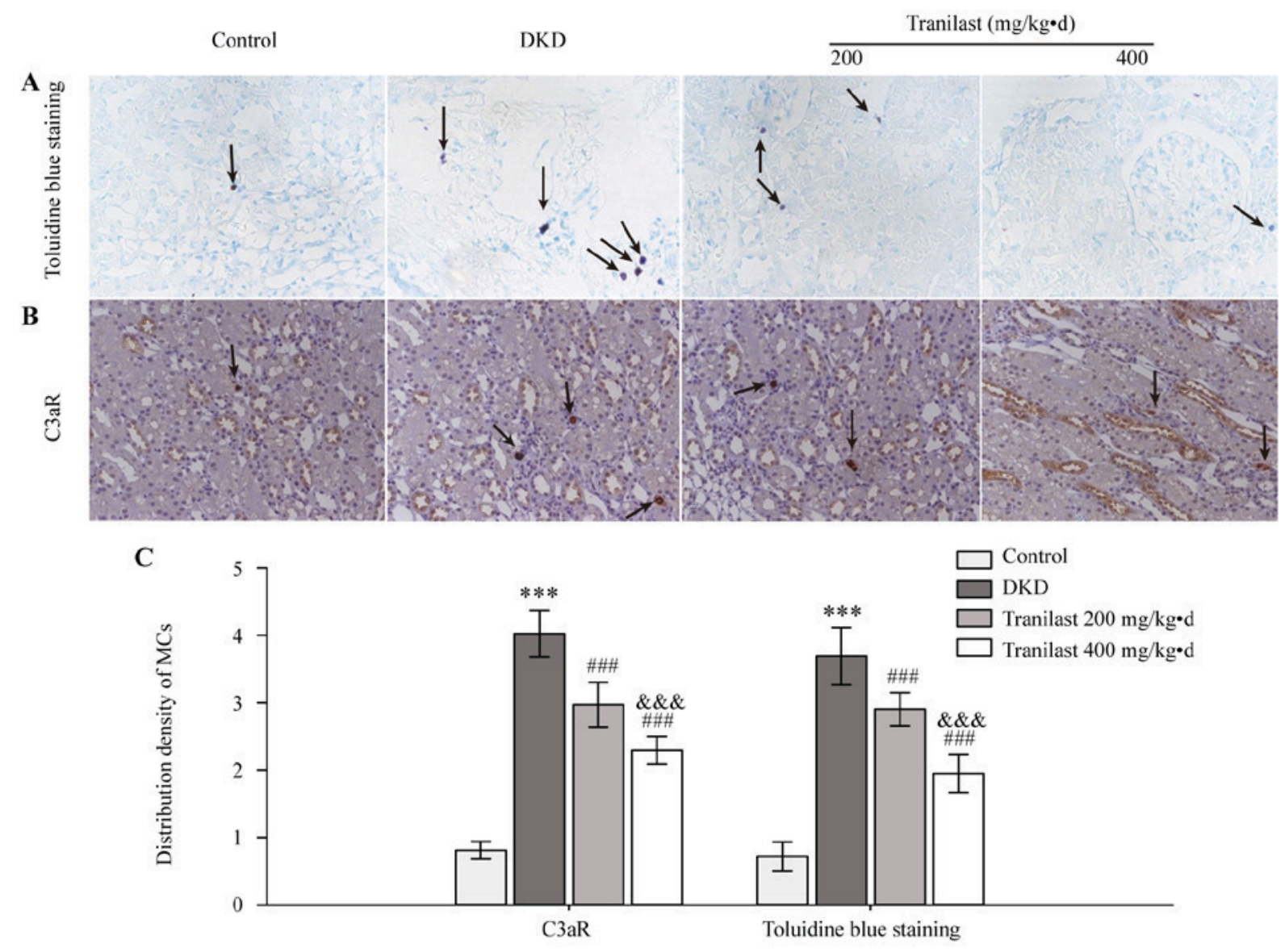

Figure 1. Tranilast reduced MC infiltration into the kidneys of DKD rats. (A) Toluidine blue staining demonstrated the distribution of MCs in the control, DKD and the groups treated with 200 and $400 \mathrm{mg} / \mathrm{kg} . \mathrm{d}$ tranilast. Magnification, x200. MCs are indicated by black arrows. (B) Immunohistochemical staining demonstrated C3aR-positive MCs in each group. Magnification, x200. C3aR-positive MCs are indicated by black arrows. (C) Distribution density of MCs in each group. ${ }^{* * *} \mathrm{P}<0.001$ vs. control group; ${ }^{\# \# "} \mathrm{P}<0.001$ vs. DKD model group; ${ }^{\& \& \&} \mathrm{P}<0.001$ vs. low-dose tranilast group (200 mg/kg.d). MC, mast cell; DKD, diabetic kidney disease; mg/kg.d, mg/kg/day; C3aR, complement C3a receptor 1.

staining is a classic method for quickly identifying mast cells, which stains mast cells purple. IHC of C3aR is another method used for detecting mast cells as mast cells express C3aR. In normal rats, mast cells, which are stained purple by toluidine blue or stained brown by IHC, were primarily localized in perivascular areas and the tubulointerstitium, and only a few mast cells were detected in the renal interstitium, but not in glomeruli (Fig. 1). However, increased numbers of mast cells were demonstrated in the renal interstitium of DKD model rats $(\mathrm{P}<0.001$; Fig. 1). Tranilast decreased the infiltration of mast cells dose-dependently ( $\mathrm{P}<0.001$; Fig. 1$)$.

Tranilast ameliorates renal tubulointerstitial fibrosis in DKD rats. The tubulointerstitial fibrosis of the kidney was observed 
using Masson's trichrome staining, which demonstrated that there was no tubular expansion and fibrous proliferation in the normal control group (Fig. 2). In a DKD model, kidneys developed tubular vacuolar degeneration and atrophy with tubulointerstitial fibrosis (Fig. 2). The fibrotic areas detected by blue staining were significantly ameliorated in the kidneys treated with tranilast in a dose-dependent manner as compared with the DKD group ( $<<0.001$; Fig. 2).

Tranilast reduces the expression of FN and Col-I in the kidneys of DKD rats. IHC staining demonstrated that FN and Col-I were primarily deposited in the glomeruli, renal tubular basement membrane and perivascular areas in the normal control rats (Fig. 3A and B). However, in the DKD rats, the expression of FN and Col-I was increased significantly in the renal interstitium, particularly in perivascular areas and inflammatory areas $(\mathrm{P}<0.001 ;$ Fig. 3A-C). Tranilast dose-dependently downregulated the expression of FN and Col-I ( $\mathrm{P}<0.001$; Fig. 3A-C). Western blot analysis and RT-qPCR demonstrated that the mRNA and protein levels of FN and Col-I were significantly upregulated in the kidneys of DKD rats, compared with those of normal control rats $(\mathrm{P}<0.001$; Fig. $3 \mathrm{D}$ and $\mathrm{E}$, respectively). Tranilast significantly downregulated the protein and mRNA expression of FN and Col-I in a dose-dependent manner compared with the DKD rats $(\mathrm{P}<0.05$; Fig. 3D and $\mathrm{E}$, respectively).

Tranilast reduces the expression of SCF and c-kit in the kidneys of DKD rats. A small amount of SCF and c-kit protein was revealed by IHC staining in the renal tubules and interstitium of normal rat kidneys. In the DKD model rats, a significantly increased level of SCF and c-kit protein were observed in renal tubular epithelial cells and interstitial inflammatory cells, compared with control rats $(\mathrm{P}<0.001$; Fig. 4A-C). Tranilast (400 mg/kg.d) downregulated the expression of SCF and c-kit $(\mathrm{P}<0.01$; Fig. 4A-C). Compared with the normal control group, the protein and mRNA levels of SCF and c-kit in the DKD model group were significantly increased $(\mathrm{P}<0.001$; Fig. 4D and E, respectively), and tranilast significantly decreased the protein and mRNA levels of SCF and c-kit in a dose-dependent manner ( $\mathrm{P}<0.05$; Fig. 4D and $\mathrm{E}$, respectively), as determined by western blotting and RT-qPCR, respectively.

Correlation of SCF and c-kit with the infiltration of mast cells and the markers of renal tubulointerstitial fibrosis. Pearson correlation analysis demonstrated a significant positive correlation between the level of SCF and the infiltration of C3aR-positive cells or the expression of FN and Col-I $(\mathrm{r}=0.941, \mathrm{P}<0.01 ; \mathrm{r}=0.896, \mathrm{P}<0.01 ;$ and $\mathrm{r}=0.858, \mathrm{P}<0.01$, respectively; Table III). In addition, a strong positive correlation was demonstrated between the level of c-kit and the infiltration of C3aR-positive cells or the expression of $\mathrm{FN}$ and Col-I ( $\mathrm{r}=0.951, \mathrm{P}<0.01 ; \mathrm{r}=0.976, \mathrm{P}<0.01$; and $\mathrm{r}=0.932, \mathrm{P}<0.01$, respectively; Table III). These results indicate that the expression of SCF and c-kit were positively correlated with the extent of mast cell infiltration and the expression of FN and Col-I.

\section{Discussion}

The incidence of chronic kidney disease (CKD) has increased substantially over the last several decades and was ranked

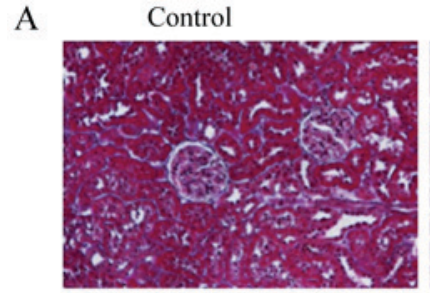

Tranilast $(200 \mathrm{mg} / \mathrm{kg} \bullet \mathrm{d})$
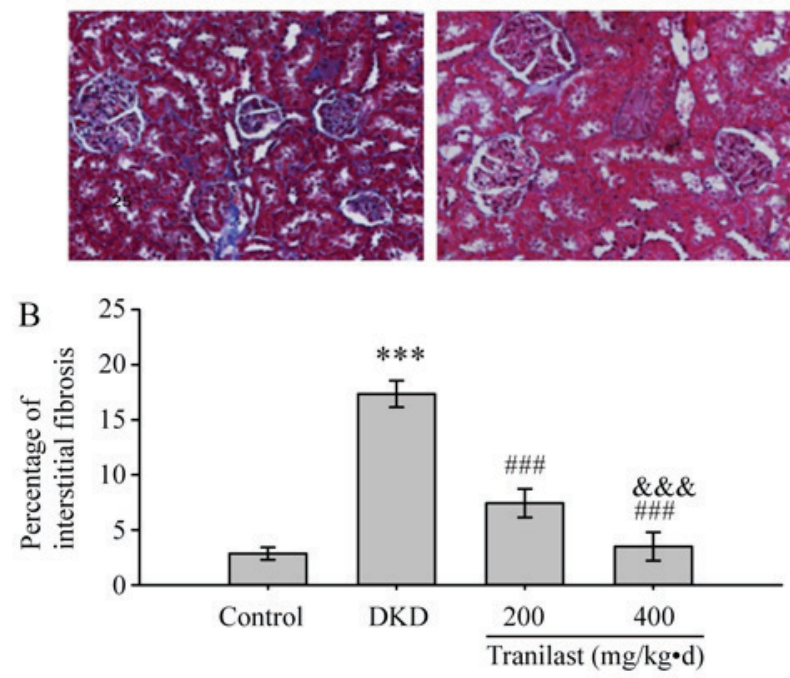

Figure 2. Tranilast reduced the tubulointerstitial fibrosis in DKD rat kidneys. (A) Masson's trichrome staining demonstrated tubulointerstitial fibrosis in each group. Magnification, x200. (B) Percentage of renal interstitial fibrosis in each group. ${ }^{* * * *} \mathrm{P}<0.001$ vs. control group; ${ }^{\# \# \#} \mathrm{P}<0.001$ vs. DKD model group; \&\&\& $\mathrm{P}<0.001$ vs. low-dose tranilast group $(200 \mathrm{mg} / \mathrm{kg}$.d $)$. DKD, diabetic kidney disease; $\mathrm{mg} / \mathrm{kg} . \mathrm{d}, \mathrm{mg} / \mathrm{kg} /$ day.

27th in 1990 and 18th in 2010 in the list of causes of global mortality (18). A previous study indicated that the overall prevalence of CKD was $10.8 \%$ in Chinese adults (19). DKD is currently a primary cause for CKD to end-stage renal disease (ESRD) in developed countries and accounts for $\sim 16.4 \%$ of all cases of ESRD in China (1). In DKD, glomerular sclerosis is observed in the progression from emerging to obvious nephropathy, whereas currently, there is increasing evidence for the importance of the interstitial fibrosis of DKD (20). Previous reports have indicated that tubulointerstitial injury may be important in the progression from moderate renal insufficiency to ESRD $(2,3)$. In addition, the underlying mechanism of renal interstitial fibrosis in DKD has not been fully elucidated, and no favorable drugs that have the ability to completely reverse renal interstitial fibrosis of DKD have currently been developed. Therefore, it is of great importance to elucidate the mechanism of interstitial fibrosis in DKD and to investigate effective therapeutic measures for slowing the progression of renal failure. In the present study, it was demonstrated that tubulointerstitial fibrosis and mast cell infiltration were upregulated in DKD model rats compared with normal control rats, and tranilast ameliorated the mast cell infiltration and the expression of FN, Col-I, SCF and c-kit. Furthermore, a positive correlation between the expression of SCF/c-kit and C3aR-positive mast cells or the markers of renal interstitial fibrosis was observed. These results not only demonstrated that mast cells served a vital role in renal interstitial fibrosis of DKD, but also illustrated that mast cells may promote renal 


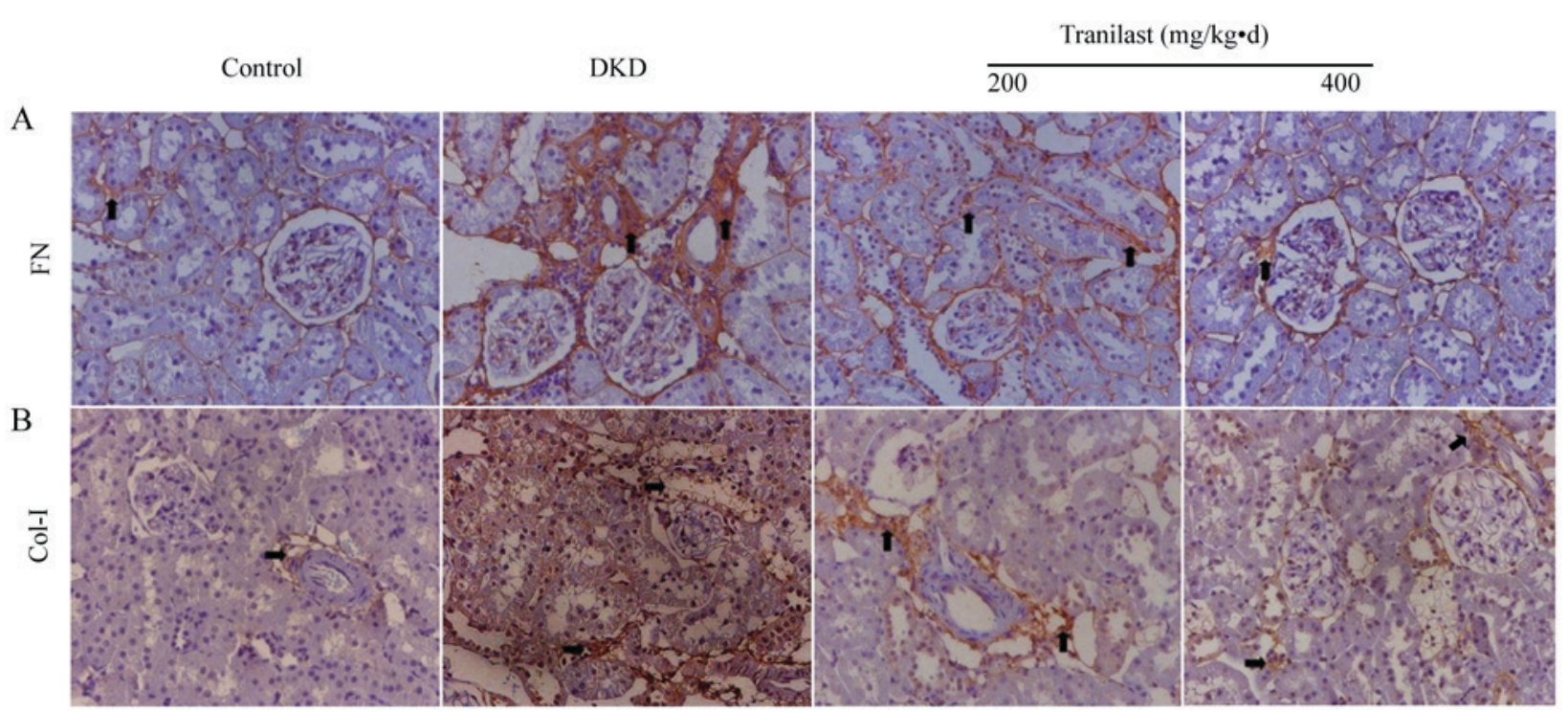

$\mathrm{C}$

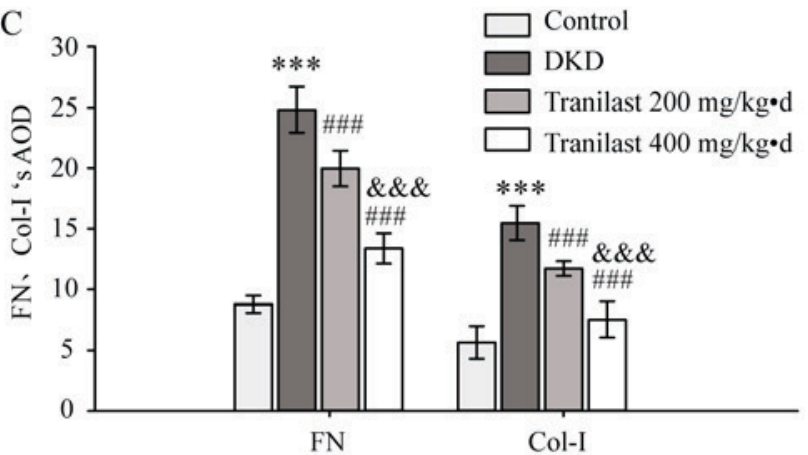

$\mathrm{E}$

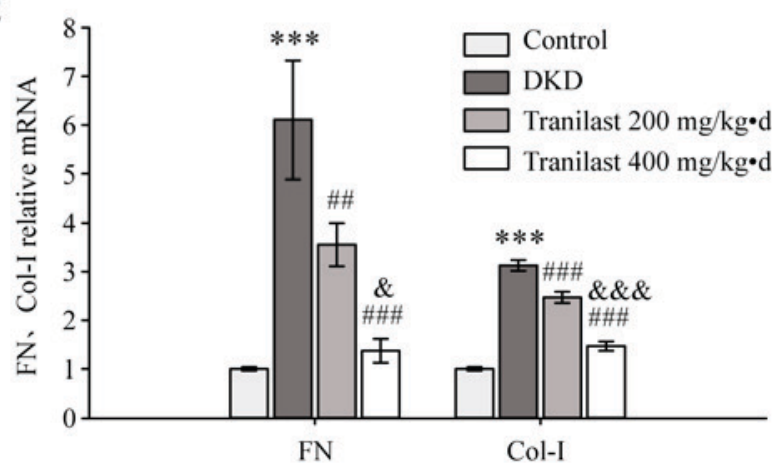

D
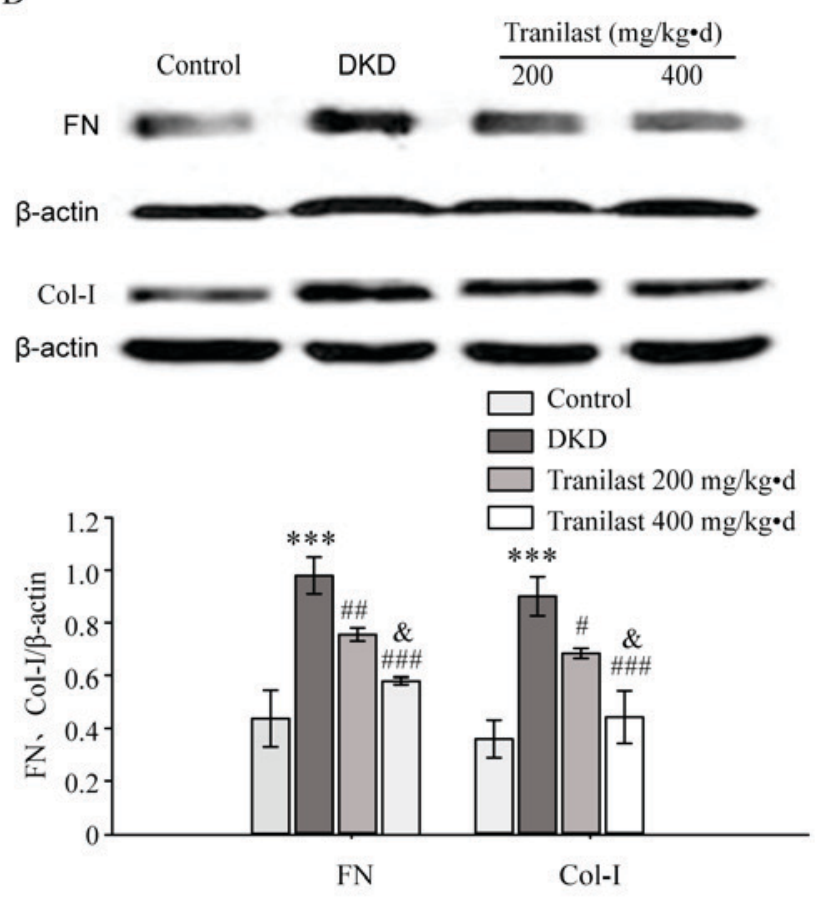

Figure 3. Tranilast reduced the expression of FN and Col-I in DKD rat kidneys. (A) Immunohistochemical staining demonstrated the expression of FN protein in each group. Magnification, x200. FN proteins are indicated by black arrows. (B) Immunohistochemical staining demonstrated the expression of Col-I protein in each group. Magnification, x200. Col-I proteins are indicated by black arrows. (C) AOD value of FN and Col-I protein in the different groups for immunohistochemical results. (D) Western blot and densitometric analysis demonstrated the expression of FN and Col-I proteins in the different groups. (E) Expression of FN and Col-I mRNA in the different groups according to Cq values generated by reverse transcription-quantitative polymerase chain reaction. ${ }^{* * *} \mathrm{P}<0.001$ vs. control group; ${ }^{\#} \mathrm{P}<0.05,{ }^{\# \#} \mathrm{P}<0.01,{ }^{\# \#} \mathrm{P}<0.001$ vs. DKD model group; ${ }^{\&} \mathrm{P}<0.05$, \&\&\& $\mathrm{P}<0.001$ vs. low-dose tranilast group $(200 \mathrm{mg} / \mathrm{kg} . \mathrm{d}) . \mathrm{FN}$, fibronectin; Col-I, collagen I; DKD, diabetic kidney disease; mg/kg.d, mg/kg/day; AOD, adjusted optical density; Cq, cycle threshold value.

interstitial fibrosis via the SCF/c-kit signaling pathway and that tranilast may attenuate renal interstitial fibrosis induced by mast cell infiltration through inhibiting the SCF/c-kit signaling pathway. Therefore, tranilast may be an effective therapeutic drug that acts by inhibiting mast cell infiltration in DKD.

It has previously been demonstrated that inflammatory cells serve an important role in the development of DKD, particularly in renal interstitial fibrosis. Macrophages, $\mathrm{T}$ lymphocytes and neutrophil granulocytes are involved in chronic inflammation and interstitial fibrosis in DKD (21-23). However, mast cells have also been reported to mediate chronic inflammation and fibrosis in the kidneys. In humans, only a limited number of mast cells reside constitutively in normal kidneys, however, in progressive renal diseases, their numbers increase substantially and mast cells represent a vital part of the inflammatory 


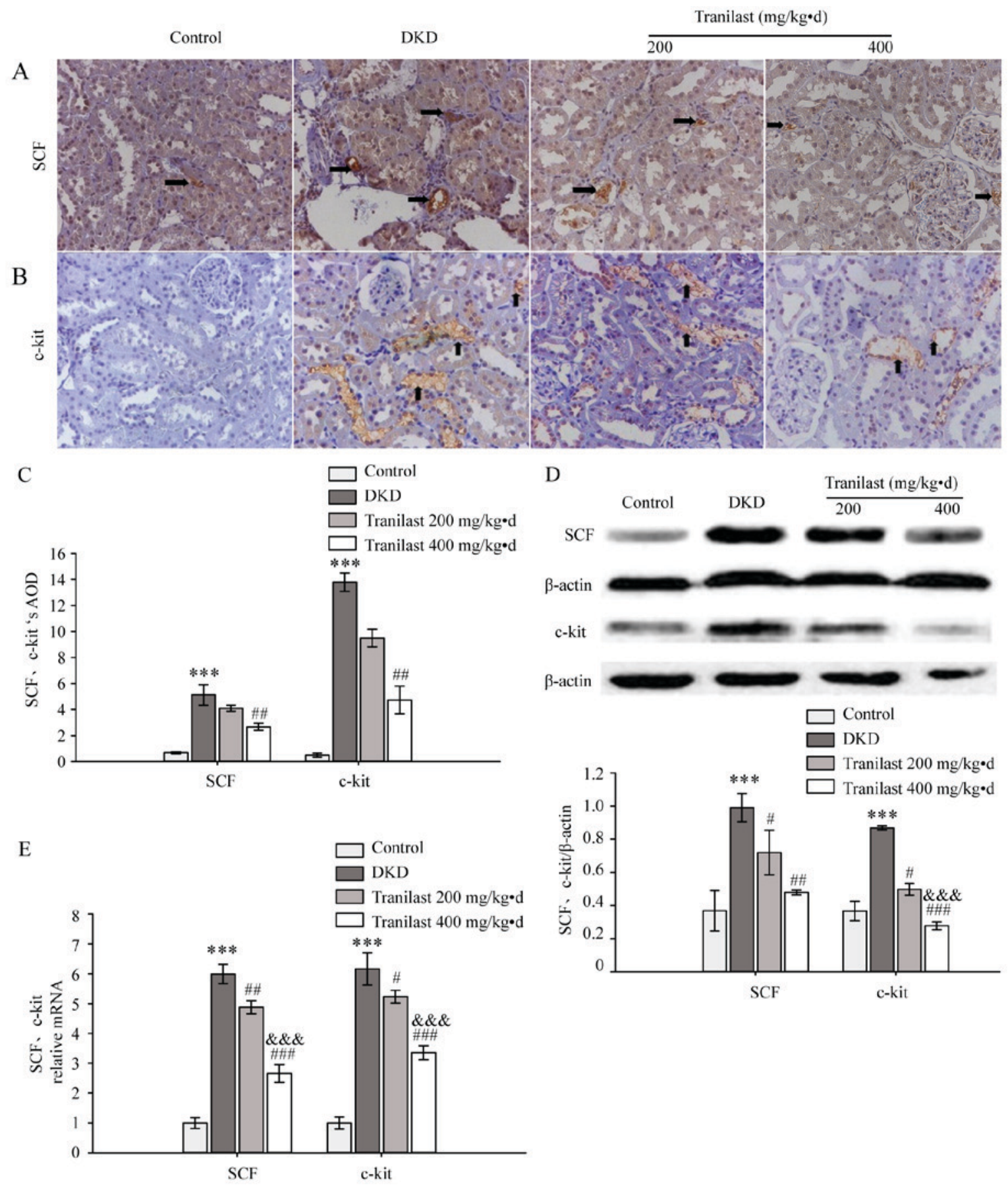

Figure 4. Tranilast reduced the expression of SCF and c-kit in DKD rat kidneys. (A) Immunohistochemical staining demonstrated the expression of SCF protein in each group. Magnification, x200. SCF proteins are indicated by black arrows. (B) Immunohistochemical staining demonstrated the expression of c-kit protein in the different groups. Magnification, x200. c-kit proteins are indicated by black arrows. (C) AOD value of SCF and c-kit protein in the different groups for immunohistochemical results. (D) Western blot and densitometric analysis demonstrated the expression of SCF and c-kit protein in the different groups. (E) Expression of SCF and c-kit mRNA in the different groups according to Cq values generated by reverse transcription-quantitative polymerase chain reaction. ${ }^{* * * *} \mathrm{P}<0.001$ vs. control group; ${ }^{\# \mathrm{P}}<0.05,{ }^{\# \#} \mathrm{P}<0.01,{ }^{\# \# \#} \mathrm{P}<0.001$ vs. DKD model group; \&\&\& $\mathrm{P}<0.001$ vs. low-dose tranilast group (200 mg/kg.d). SCF, stem cell factor; c-kit, proto-oncogene c-kit; DKD, diabetic kidney disease; mg/kg.d, mg/kg/day; AOD, adjusted optical density; Cq, cycle threshold value.

cell infiltration into the renal interstitium (24). Certain studies have demonstrated that mast cells infiltrate the renal interstitium in various nephropathies, including diabetic nephropathy, lupus nephritis and IgA nephropathy $(6,25,26)$. Our previous study demonstrated that mast cells increased in the renal interstitium of rats with protein-overload nephropathy, indicating that mast cells may serve an important role in renal interstitial fibrosis induced by proteinuria (27). Consistent with the above studies, in the present study, it was demonstrated that mast cell infiltration into the renal interstitium of the DKD model group was increased compared with the control group, which indicates that mast cells may serve an important role in the progression of DKD.

Mast cells release large amounts of cytokines, chemokines and growth factors, including chymotrypsin, renin, histamine, preformed tumor necrosis factor- $\alpha$, interleukin- 17 
Table III. Correlation of SCF and c-kit with mast cell infiltration and markers of renal interstitial fibrosis.

\begin{tabular}{lcclll}
\hline & \multicolumn{2}{c}{ SCF } & & \multicolumn{2}{c}{ c-kit } \\
\cline { 2 - 3 } \cline { 6 - 7 } & r & P-value & & r & P-value \\
\hline C3aR-positive mast cells & 0.941 & $<0.01$ & & 0.951 & $<0.01$ \\
FN & 0.896 & $<0.01$ & & 0.976 & $<0.01$ \\
Col-I & 0.858 & $<0.01$ & & 0.932 & $<0.01$
\end{tabular}

$\mathrm{SCF}$, stem cell factor; c-kit, proto-oncogene c-kit; r, coefficient of correlation; $\mathrm{C} 3 \mathrm{aR}$, complement $\mathrm{C} 3 \mathrm{a}$ receptor 1 ; $\mathrm{FN}$, fibronectin; Col-I, collagen-I.

and TGF- $\beta$. Inflammatory mediators lead to the activation of local inflammation and increased expression of TGF- $\beta$, which is involved in the occurrence of renal interstitial fibrosis (25). Activated mast cells also secrete chymase, an enzyme that is able to cleave the latent form of TGF- $\beta$ from cell membranes to form active TGF- $\beta$, resulting in interstitial fibrosis $(25,28)$. $\mathrm{SCF}$, mast cell growth factor or steel factor, is a key chemoattractant for mast cell precursor migration and a key survival and differentiation factor for mast cells. In addition, SCF was also reported to synergistically enhance antigen-induced degranulation and cytokine production of mast cells (29-31). It has been reported that epithelial cells and fibroblasts produce the soluble form of SCF, which binds to a receptor of SCF on the membrane of mast cells that is termed c-kit (32). c-kit, also known as CD117, is a transmembrane glycoprotein receptor that possesses tyrosine kinase activity. Additional reports have indicated that the SCF/c-kit signaling pathway may be a major signaling pathway involved in mast cell activation (30). It was also demonstrated that the expression of SCF and c-kit was significantly increased in kidneys with serum nephrotoxic nephritis (33). The present study demonstrated that the expression of SCF and c-kit increased in the tissue of the DKD model group, and the expression of SCF and c-kit was positively correlated with C3aR-positive mast cell infiltration and the markers of renal interstitial fibrosis. The above results indicate that mast cells may promote renal interstitial fibrosis of DKD via the $\mathrm{SCF} / \mathrm{c}$-kit signaling pathway.

Therefore, inhibiting mast cell survival, differentiation and release of inflammatory mediators via the $\mathrm{SCF} / \mathrm{c}$-kit signaling pathway may be a potential therapeutic target for renal interstitial fibrosis. Tranilast, an anti-allergic agent, has been reported to stabilize the mast cell membrane and inhibit the release of inflammatory granules. It is generally used in the treatment of inflammatory diseases, including bronchial asthma, atypical dermatitis, allergic conjunctivitis, keloids and hypertrophic scars. Furthermore, beneficial effects of tranilast have also been reported in various diseases, which include fibrotic and proliferative disorders, tumor development, cardiovascular and autoimmune disorders, ocular diseases, diabetes and kidney diseases (7). Kaneyama et al (8) demonstrated that tranilast exerted a protective effect on renal interstitial fibrosis in rats with unilateral ureteral obstruction. Tranilast was also demonstrated to attenuate renal interstitial fibrosis by reducing the expression of TGF- $\beta$ (11), which may be associated with its role as an antioxidant, inhibiting the production of inflammatory factors and reducing the synthesis of collagen.

In the present study, the infiltration of mast cells, and the expression of FN, Col-I, SCF and c-kit, was reduced in tranilast treatment groups compared with the DKD model group, which demonstrates tranilast may attenuate the infiltration of mast cells to reduce renal interstitial fibrosis by inhibiting the expression of SCF and c-kit. Therefore, a novel target for the treatment of renal interstitial fibrosis of DKD using tranilast has been identified. However, the detailed molecular mechanism of mast cell-induced renal interstitial fibrosis via the SCF/c-kit signaling pathway remains to be investigated. In addition, the mechanism by which tranilast prevents renal interstitial fibrosis through inhibition of mast cell infiltration mediated by the $\mathrm{SCF} / \mathrm{c}-\mathrm{kit}$ signaling pathway also requires further investigation.

\section{Acknowledgements}

The authors would like to thank Professor Jun Li, Professor Lin Sun, Professor Hong Liu and Professor Fu-you Liu, who have been working in the Department of Nephrology, the Second Xiangya Hospital, Central South University, for their technical support for this research and for editing this manuscript.

\section{Funding}

The present study was supported by the National Natural Science Foundation of China (grant nos. 81100486 and 81370792) and the Hunan science and technology project (grant no. 2017SK2072).

\section{Availability of data and materials}

The analyzed data sets generated during the study are available from the corresponding author on reasonable request.

\section{Authors' contributions}

YL conceived, designed and supervised the study. DDY made the partial experiment, analyzed and interpreted the data, and was a major contributor in writing the manuscript. JHL made the experiment and analyzed the data, and wrote the manuscript. ZZY and YJL participated in the analysis of the data and the writing of the manuscript. All the authors read and approved the final manuscript.

\section{Ethics approval and consent to participate}

All animals used in the present study were appropriately processed following protocols approved in advance by the Animal Care and Use Committee at Central South University. All procedures performed in experiments with animals were in accordance with the ethical standards of the Department of Nephrology, Second Xiangya Hospital at which the present study was conducted.

\section{Consent for publication}

Not applicable. 


\section{Competing interests}

The authors declare that they have no competing interests.

\section{References}

1. Liu ZH: Nephrology in China. Nat Rev Nephrol 9: 523-528, 2013.

2. Tervaert TW, Mooyaart AL, Amann K, Cohen AH, Cook HT, Drachenberg CB, Ferrario F, Fogo AB, Haas M, de Heer E, et al: Pathologic classification of diabetic nephropathy. J Am Soc Nephrol 21: 556-563, 2010.

3. Najafian B, Alpers CE and Fogo AB: Pathology of human diabetic nephropathy. Contrib Nephrol 170: 36-47, 2011.

4. Elmarakby AA and Sullivan JC: Relationship between oxidative stress and inflammatory cytokines in diabetic nephropathy. Cardiovasc Ther 30: 49-59, 2012.

5. Moresco RN, Sangoi MB, De Carvalho JA, Tatsch E and Bochi GV: Diabetic nephropathy: Traditional to proteomic markers. Clin Chim Acta 421: 17-30, 2013.

6. Zheng JM, Yao GH, Cheng Z, Wang R and Liu ZH: Pathogenic role of mast cells in the development of diabetic nephropathy: A study of patients at different stages of the disease. Diabetologia 55 801-811, 2012.

7. Darakhshan S and Pour AB: Tranilast: A review of its therapeutic applications. Pharmacol Res 91: 15-28, 2015.

8. Kaneyama T, Kobayashi S, Aoyagi D and Ehara T: Tranilast modulates fibrosis, epithelial-mesenchymal transition and peritubular capillary injury in unilateral ureteral obstruction rats. Pathology 42: 564-573, 2010.

9. Kazama I, Baba A, Endo Y, Toyama H, Ejima Y, Matsubara M and Tachi M: Mast cell involvement in the progression of peritoneal fibrosis in rats with chronic renal failure. Nephrology (Carlton) 20: 609-616, 2015.

10. See F, Watanabe M, Kompa AR, Wang BH, Boyle AJ, Kelly DJ, Gilbert RE and Krum H: Early and delayed tranilast treatment reduces pathological fibrosis following myocardial infarction. Heart Lung Circ 22: 122-132, 2013.

11. Tao Y, Hu L, Li S, Liu Q, Wu X, Li D, Fu P, Wei D and Luo Z: Tranilast prevents the progression of chronic cyclosporine nephrotoxicity through regulation of transforming growth factor $\beta /$ Smad pathways. Transplant Proc 43: 1985-1988, 2011.

12. Tan SM, Zhang Y, Cox AJ, Kelly DJ and Qi W: Tranilast attenuates the up-regulation of thioredoxin-interacting protein and oxidative stress in an experimental model of diabetic nephropathy. Nephrol Dial Transplant 26: 100-110, 2011.

13. Li Y, Chen Q, Liu FY, Peng YM, Hou T, Duan SB, Li J, Luo JH, Sun L and Ling GH: Norcantharidin attenuates tubulointerstitial fibrosis in rat models with diabetic nephropathy. Ren Fail 33: 233-241, 2011

14. Srinivasan K, Viswanad B, Asrat L, Kaul CL and Ramarao P: Combination of high-fat diet-fed and low-dose streptozotocin-treated rat: A model for type 2 diabetes and pharmacological screening. Pharmacol Res 52: 313-320, 2005.

15. Katz A, Caramori ML, Sisson-Ross S, Groppoli T, Basgen JM and Mauer M: An increase in the cell component of the cortical interstitium antedates interstitial fibrosis in type 1 diabetic patients. Kidney Int 61: 2058-2066, 2002.
16. Wang J, Ding J, Jiao H, Honardoust D, Momtazi M, Shankowsky HA and Tredget EE: Human hypertrophic scar-like nude mouse model: Characterization of the molecular and cellular biology of the scar process. Wound Repair Regen 19: 274-285, 2011.

17. Livak KJ and Schmittgen TD: Analysis of relative gene expression data using real-time quantitative PCR and the 2(-Delta Delta C(T)) method. Methods 25: 402-408, 2001.

18. Jha V, Garcia-Garcia G, Iseki K, Li Z, Naicker S, Plattner B, Saran R, Wang AY and Yang CW: Chronic kidney disease: Global dimension and perspectives. Lancet 382: 260-272, 2013.

19. Zhang L, Wang F, Wang L, Wang W, Liu B, Liu J, Chen M, He Q, Liao Y, Yu X, et al: Prevalence of chronic kidney disease in China: A cross-sectional survey. Lancet 379: 815-822, 2012.

20. Slyne J, Slattery C, McMorrow T and Ryan MP: New developments concerning the proximal tubule in diabetic nephropathy: In vitro models and mechanisms. Nephrol Dial Transplant 4 (30 Suppl): iv60-iv67, 2015.

21. Eddy AA: Overview of the cellular and molecular basis of kidney fibrosis. Kidney Int Suppl (2011) 4: 2-8, 2014

22. Zeisberg M and Kalluri R: Cellular mechanisms of tissue fibrosis. 1. Common and organ-specific mechanisms associated with tissue fibrosis. Am J Physiol Cell Physiol 304: C216-C225, 2013.

23. Ribatti D and Crivellato E: Mast cell ontogeny: An historical overview. Immunol Lett 159: 11-14, 2014

24. Madjene LC,Pons M,Danelli L,Claver J,AliL,Madera-Salcedo IK, Kassas A, Pellefigues C, Marquet F, Dadah A, et al: Mast cells in renal inflammation and fibrosis: Lessons learnt from animal studies. Mol Immunol 63: 86-93, 2015.

25. Kaczmarczyk K, Kosalka J, Soja J, Kuzniewski M, Musial J and Okon K: Renal interstitial mast cell counts differ across classes of proliferative lupus nephritis. Folia Histochem Cytobiol 52: 218-224, 2014.

26. Liu H, Liu F, Peng Y, Liu Y, Li L, Tu X, Cheng M, Xu X, Chen X, Ling $G$ and Sun L: Role of mast cells, stem cell factor and protease-activated receptor- 2 in tubulointerstitial lesions in $\operatorname{Ig} \mathrm{A}$ nephropathy. Inflamm Res 59: 551-559, 2010.

27. Li Y, Zhou L, Liu F, Peng Y, Li J, Sun L, Duan S, Ling G, Chen X, Jiang W and Xia Y: Mast cell infiltration is involved in renal interstitial fibrosis in a rat model of protein-overload nephropathy. Kidney Blood Press Res 33: 240-248, 2010.

28. Taipale J, Lohi J, Saarinen J, Kovanen PT and Keski-Oja J: Human mast cell chymase and leukocyte elastase release latent transforming growth factor-beta 1 from the extracellular matrix of cultured human epithelial and endothelial cells. J Biol Chem 270: 4689-4696, 1995.

29. Smrž D, Bandara G, Zhang S, Mock BA, Beaven MA, Metcalfe DD and Gilfillan AM: A novel KIT-deficient mouse mast cell model for the examination of human KIT-mediated activation responses. J Immunol Methods 390: 52-62, 2013.

30. HalovaI,DraberovaL and DraberP: Mastcell chemotaxis-chemoattractants and signaling pathways. Front Immunol 3: 119, 2012.

31. Gilfillan AM and Tkaczyk C: Integrated signalling pathways for mast-cell activation. Nat Rev Immunol 6: 218-230, 2006.

32. Miyamoto K, Kobayashi T, Hayashi Y, Zhang Y, Hara Y, Higashine M, Shiraishi A and Ohashi Y: Involvement of stem cell factor and c-kit in corneal wound healing in mice. Mol Vis 18: 1505-1515, 2012.

33. El Kossi MM, Haylor JL, Johnson TS and El Nahas AM: Stem cell factor in a rat model of serum nephrotoxic nephritis. Nephron Exp Nephrol 108: e1-e10, 2008. 